\title{
Diet and nocturnal foraging in cardinalfishes (Apogonidae) at One Tree Reef, Great Barrier Reef, Australia
}

\author{
Michael J. Marnane*, David R. Bellwood \\ Department of Marine Biology, James Cook University, Townsville, Queensland 4811, Australia
}

\begin{abstract}
Cardinalfishes (family Apogonidae) form a major component of nocturnal planktivore assemblages on coral reefs. In order to assess their trophic role on reefs, we examined diet, diel feeding behaviour and nocturnal foraging in 7 species in the lagoon at One Tree Reef, Great Barrier Reef, Australia. Between 64 and $93 \%$ of fish collected at dawn had identifiable material in the stomach compared with 5 to $36 \%$ of fish collected at dusk, suggesting that all 7 species were predominantly nocturnal feeders. The movement of apogonids between resting sites and feeding grounds was examined using day and night visual surveys. Apogonids shared restricted resting habitats by day but moved into a range of habitats at night. Species were spatially segregated at night, both horizontally and vertically in the water column. Most species had generalised diets containing primarily demersal plankton and benthic invertebrates, suggesting a role in recycling rather than importation of nutrients and energy on reefs. Dietary differences among species appeared to be driven largely by their feeding positions in the water column at night. Since apogonids feed in a range of habitats, then return to restricted resting sites during the day, they are likely to play an important role in concentrating nutrients and energy on reefs, providing localised and predictable resources for both predators and detritivore communities.
\end{abstract}

KEY WORDS: Apogonidae $\cdot$ Cardinalfishes $\cdot$ Coral reef $\cdot$ Feeding $\cdot$ Habitat use $\cdot$ Movement

\section{INTRODUCTION}

Nocturnal planktivores are functionally distinct from their diurnal counterparts on coral reefs (Hobson 1991). Diurnal planktivores generally feed on small prey of oceanic origin (Hobson \& Chess 1978) whereas nocturnal planktivores usually feed on much larger prey (Hobson \& Chess 1978) of reef origin (Hobson \& Chess 1979). Nocturnal planktivores often migrate away from their shelter sites to forage in a range of reef and non-reef habitats (e.g. Hobson 1974, Ogden \& Erlich 1977, Nagelkerken et al. 2000) while their diurnal counterparts typically feed in the water column in close proximity to the reef (Hobson 1991). Although

*E-mail: mmarnane@wcs.org the role of diurnal planktivores in reef trophodynamics has received much attention, the role of nocturnal planktivores has been largely overlooked. Most nocturnal planktivores are cryptic by day and are therefore often underestimated or missed in standard daytime visual censuses of reef fish communities (Ackerman \& Bellwood 2000). In addition, there have been few studies of nocturnal planktivores during their active, feeding phase, probably due to the logistical constraints of working underwater at night.

The family Apogonidae (cardinalfishes) forms the dominant component of nocturnal planktivore assemblages on Indo-Pacific reefs (Allen 1993), commonly ranking second to third highest of all reef fish families in terms of both abundance and species diversity (Bellwood 1996). Apogonids are small (generally $<10 \mathrm{~cm}$ ), mostly nocturnal predators of plankton, fish and ben- 
thic invertebrates (Vivien 1975). By day, apogonids rest in caves or amongst branching coral, often forming dense, multi-specific aggregations (Greenfield \& Johnson 1990). Apogonids consume prey from both reef and non-reef sources, including open water, sand and seagrass habitats (Vivien 1975). They are also significant predators of demersal plankton (Vivien 1975, Chave 1978), a trophic pathway that has received little attention on coral reefs (Parrish 1989). Apogonids may return to the same resting sites daily over extended periods of time (Kuwamura 1985, Okuda \& Yanagisawa 1996, Marnane 2000), and thus may play a significant role in the concentration of energy and nutrients at localised, predictable sites on reefs (cf. Bray et al. 1981).

Despite their prominence on reefs, apogonids remain one of the least studied of the major families of reef fishes. A generalist diet, consisting mostly of demersal plankton and benthic invertebrates has been described for apogonids from the Marshall Islands (Hiatt \& Strasburg 1960, Hobson \& Chess 1978), Hawaii (Chave 1978) and Madagascar (Vivien 1975). However, comparable data on the feeding ecology of Indo-West Pacific apogonids are lacking. A number of studies have examined apogonid distribution patterns during the day (e.g. Vivien 1975, Dale 1978, Greenfield \& Johnston 1990, Finn \& Kingsford 1996); however, except for qualitative observations (e.g. Hiatt \& Strasburg 1960, Livingston 1971, Chave 1978, Allen 1993), there are no published accounts of nocturnal distribution patterns. In order to evaluate the trophic role of apogonids on reefs, it is necessary to combine dietary information with both diurnal and nocturnal distribution data. The specific objectives of this study, therefore, were to describe: (1) foraging patterns, (2) diel feeding patterns, and (3) diet, in 7 common apogonid species from the Great Barrier Reef.

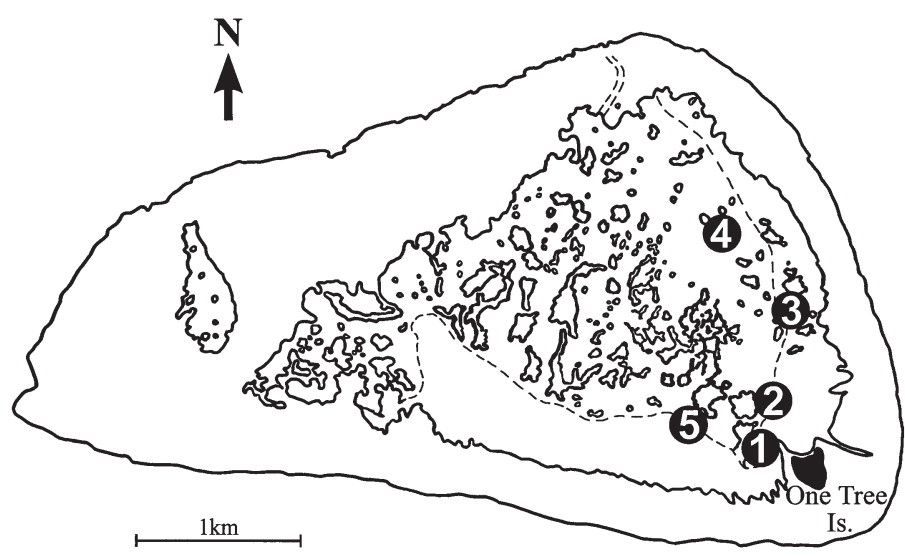

Fig. 1. One Tree Reef study sites used in day and night censuses

\section{MATERIALS AND METHODS}

Study site and species. This study was carried out within the One Tree Reef lagoon, southern Great Barrier Reef, Australia (152 03' E, $\left.23^{\circ} 30^{\prime} \mathrm{S}\right)$. One Tree Reef contains a shallow lagoon (average depth $=3$ to $5 \mathrm{~m}$ ) with a well-defined outer reef wall and an inner matrix of patch reefs and micro-atolls (Fig. 1). The 7 most abundant apogonid species in the lagoon were studied: Apogon cyanosoma, Apogon doederlini, Apogon exostigma, Apogon guamensis, Archamia leai, Cheilodipterus artus and Cheilodipterus quinquilineatus. Only large juvenile and adult apogonids (>30 mm standard length) were examined owing to difficulties in identifying newly settled individuals of some species and the possibility of ontogenetic shifts in the diet (cf. Fishelson \& Sharon 1997) and habitat use (Finn \& Kingsford 1996) of early juveniles.

Foraging movements. The nocturnal movements of apogonids between resting and feeding sites were examined through a direct comparison of day and night distributions. Censuses were conducted over $5 \mathrm{~d}$ surrounding the quarter moon phase during November 1998, February 1999 and July 1999. During each of the 3 sampling periods 5 randomly placed transects were laid perpendicular to the reef at each of 5 microatolls selected randomly from a range of suitable sites (Fig. 1). Quadrats of an estimated $8 \mathrm{~m}^{2}$ and the water column immediately above them were surveyed at points along the transect within all reef habitats, including the reef flat, crest, slope, base and at distances of 5, 10, 20 and $30 \mathrm{~m}$ from the reef over the sand areas between micro-atolls (1 quadrat per habitat type). The observers remained outside the quadrat during the census. All apogonids present within the quadrat were recorded including an estimate of their standard lengths, heights above the substratum, and the nearest microhabitat type (reef, sand or water column). Specimens were recorded as being from the 'water column' microhabitat if further than $30 \mathrm{~cm}$ from the substratum. Quadrats were surveyed between 09:00 and 15:00 $\mathrm{h}$, then resurveyed the same night between 21:00 and 03:00 h.

In order to reduce diver effects at night, only available moonlight was used to locate census points on the transect. Once the census points were located, quadrats and the water column immediately above them were briefly illuminated by 2 divers using $2 \times 12 \mathrm{~V}$ underwater halogen lights. Apogonids generally 'froze' in position when illuminated. All apogonids present within the quadrat immediately upon illumination were recorded, including estimates of their standard length, height above the substra- 
tum and nearest microhabitat type. Illumination periods generally lasted a few minutes. Any specimens that entered the quadrat after initial illumination were excluded from the survey. Specimens which could not be positively identified were collected after the census. This was achieved by one diver stunning the target fish with torch-light while the second diver collected the fish using hand nets. These fish were then placed in individual, labelled bags and later identified in the laboratory.

Feeding patterns. The diel feeding patterns of each species were assessed through examination of stomach contents of fish collected at dawn and dusk. Fish were collected around dawn (05:30 to 07:00 h) and dusk (17:00 to $18: 30$ h) during November 1998, February 1999 and July 1999 from at least 2 randomly chosen sites per time of day and sampling period within the lagoon. Fish were collected on SCUBA using hand nets and small hand spears. In both dawn and dusk samples, fish were collected from their resting sites. Fish were immediately killed underwater, then placed on ice within $30 \mathrm{~min}$ and frozen within $2 \mathrm{~h}$ of collection. Fish were later dissected and the stomach contents removed, recording the presence of identifiable items. Identifiable material had presumably been recently consumed and had not yet undergone significant digestion.

Diet was assessed through the examination of stomach contents of specimens collected at night (21:00 to 03:00 h) during late February 1999 from 3 randomly chosen sites within the lagoon. At each site, species were collected from across the entire range of habitats in which they occurred at night. Fish were collected by scuba divers with hand nets after stunning them with torchlight. Fish were killed immediately then placed on ice within $30 \mathrm{~min}$ and frozen within $2 \mathrm{~h}$. Stomach contents were later removed, identified and placed in major taxonomic categories. The mean weight of each prey taxonomic category for each apogonid species was calculated by weighing a random sample $(>10$ where possible) of intact prey specimens. Mean prey item weights for each prey category were then multiplied by mean prey occurrences in the stomachs of each apogonid species to provide an estimate of the mass of material in each dietary category for each apogonid species. Combined error terms were calculated using Goodman's estimator, following Travis (1982):

$$
\mathrm{SE}(\bar{x} \times \bar{y})^{2}=\bar{x}^{2} \times \mathrm{SE}_{\bar{y}}^{2}+\bar{y}^{2} \times \mathrm{SE}_{\bar{x}}^{2}+\mathrm{SE}_{\bar{x}}{ }^{2} \times \mathrm{SE}_{\bar{y}}^{2}
$$

where $\bar{X}=$ mean prey item weight in each prey category; $\bar{y}=$ mean number of prey items from each prey category per individual fish; $\mathrm{SE}_{\bar{x}}=$ standard error of mean prey item weight; $\mathrm{SE}_{\bar{y}}=$ standard error of mean prey number.
Statistical analyses. Data on day and night distributions of apogonids violated assumptions of homoscedasticity and normality. Distributions of each species were therefore analysed using chi-square tests of independence among the 3 survey periods. Distribution data were pooled among sites and habitats where necessary to meet chi-square assumptions. Data on the heights of apogonids above the substratum violated assumptions of homoscedasticity and were analysed using Kruskal-Wallis tests followed by post-hoc Tukeytype multiple comparisons, following Zar (1984). The dietary relationships between species were examined using principle components analysis (PCA). PCA was carried out on the correlation matrix of dietary data (see Table 2) before they were converted to percentages. Pearson's correlation was used to examine the relationship between height above substratum and principle component 1 scores from the principle component analysis. All analyses were carried out on SPSS v. 9.0 (SPSS Inc., Chicago, IL).

\section{RESULTS}

\section{Foraging movements}

Surveys conducted during the day showed a restricted distribution of apogonids at resting sites, primarily on the reef slope and at the reef base (Fig. 2A). Although the abundance of apogonids differed at each time of year, patterns of habitat use by each species were not significantly different among the 3 sampling periods (all chi-squared values $<$ critical values; $\mathrm{p}=$ 0.09 to 0.69 ). The 3 sampling periods were therefore pooled for analyses. All species were predominantly located within caves or branching coral (indicated by negative heights above the substratum in Fig. 2A). Although there was a significant difference in mean heights above the substratum among species during the day (Kruskal-Wallis, $H=175$, df $=6, \mathrm{p}<0.001$ ), Tukey-type multiple comparisons revealed overlapping height distributions among Apogon doederlini, A. exostigma, A. guamensis, and Archamia leai $(Q=0.04$ to 2.91, $\mathrm{k}=7, \mathrm{p}>0.05$ ) and between Cheilodipterus artus and $C$. quinquilineatus $(Q=1.11, \mathrm{k}=7, \mathrm{p}>0.5)$.

Night surveys showed that the majority of species foraged in different habitats to their diurnal resting sites (Fig. 2B). For example, Apogon cyanosoma was recorded primarily in caves in the reef base by day and occurred almost exclusively on the reef flat at night, whilst $A$. doederlini occurred on the reef slope and base by day and foraged over sand between microatolls at night. Furthermore, in contrast to daytime distributions, there was a strong degree of spatial separation between species at night, with little overlap in 

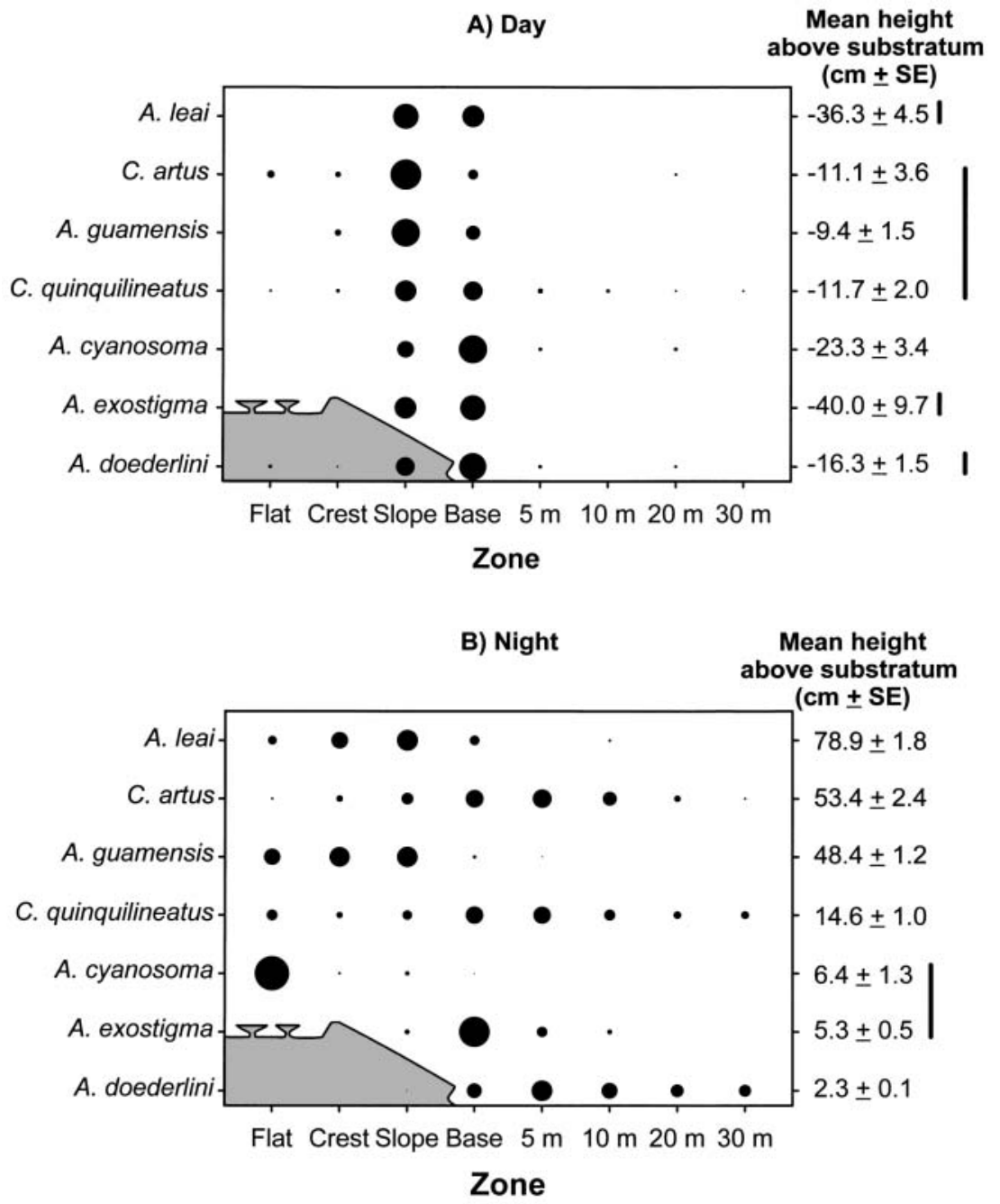

Fig. 2. Bubble plots of proportional habitat use by 7 apogonid species during (A) day (09:00-15:00 h) and (B) night (21:00-03:00 h). Circle areas represent the number of fish recorded from each habitat as a proportion of the total number of fish of each species recorded across all habitats (based on 75 quadrat censuses; fish sample sizes in Table 1). Negative heights above substratum indicate that fish were in caves or within branching coral. Overlapping mean heights above substratum among species are indicated by bars either horizontal or vertical distribution patterns (Fig. 2B). Mean heights above the substratum at night were significantly different among species (Kruskal-Wallis, $H=2718$, df $=6$, p < 0.001) (Fig. 2B) with a post-hoc multiple comparison suggesting overlapping nocturnal vertical distributions in only A. cyanosoma and A. exostigma (Tukey-type comparison, $Q=0.41, \mathrm{k}=$ $7, \mathrm{p}>0.5)$. In addition, most species showed a strong link with specific microhabitat types at night (Table 1). A. doederlini, A. cyanosoma and $A$. exostigma were located above sand more than $87 \%$ of the time, whilst Archamia leai and Apogon guamensis were located in the water column $82 \%$ and $78 \%$ of the time respectively. Cheilodipterus artus and C. quinquilineatus did not show a strong link with any one microhabitat and were frequently located in the water column and above sand and reef microhabitats at night (Table 1).

\section{Feeding patterns}

In all 7 species, a large proportion of individuals had identifiable material in the stomachs when collected at dawn, whereas fish collected at dusk usually had empty stomachs or small fragments of heavily digested material (Fig. 3). The only major exception was Apogon cyanosoma, where identifiable items were found in the stomachs of $36 \%$ of specimens collected at dusk.

Table 1. Distribution of species with respect to microhabitat type. Data represent the percent occurrence of each species with respect to the nearest microhabitat type (within $30 \mathrm{~cm}$ ); $\mathrm{n}=$ total number of fish recorded during surveys

\begin{tabular}{|c|c|c|c|c|c|c|c|c|}
\hline \multirow[t]{2}{*}{ Species } & \multicolumn{2}{|c|}{ Sand (\%) } & \multicolumn{2}{|c|}{ Reef (\%) } & \multicolumn{2}{|c|}{ Water column (\%) } & \multicolumn{2}{|c|}{$\mathrm{n}$} \\
\hline & Day & Night & Day & Night & Day & Night & Day & Night \\
\hline Apogon cyanosoma & 3 & 87 & 92 & 12 & 5 & 1 & 264 & 143 \\
\hline Apogon doederlini & 5 & 93 & 91 & 5 & 4 & 2 & 650 & 1108 \\
\hline Apogon exostigma & 2 & 90 & 98 & 8 & 0 & 2 & 54 & 209 \\
\hline Apogon guamensis & 0 & 0 & 100 & 22 & 0 & 78 & 60 & 834 \\
\hline Archamia leai & 0 & 0 & 98 & 18 & 2 & 82 & 164 & 688 \\
\hline Cheilodipterus artus & 14 & 15 & 66 & 34 & 20 & 51 & 155 & 195 \\
\hline \multirow[t]{2}{*}{ Cheilodipterus quinquilineatus } & 13 & 29 & 62 & 36 & 25 & 35 & 447 & 276 \\
\hline & & & & & & Total & 1794 & 3453 \\
\hline
\end{tabular}




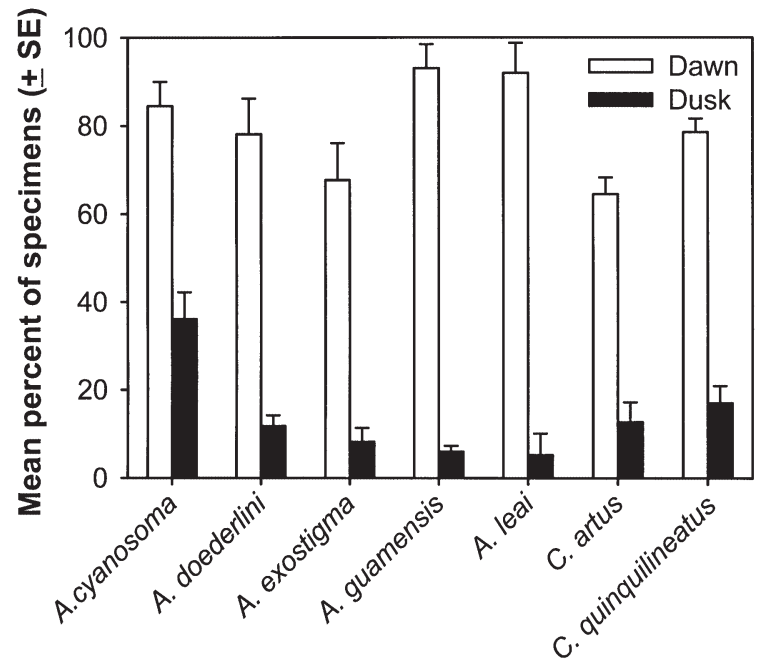

Fig. 3. Mean percent of specimens collected at dawn (05:30-07:00 h) and dusk (17:00-18:30 h) with identifiable prey items in their stomachs. SE values based on 3 sample periods: November, February and July

All of the species examined, except for Cheilodipterus artus, consumed a wide range of prey categories (Table 2). The dominant taxa consumed by most species were crustaceans (mainly small decapods and decapod larvae). C. artus was an exception and fed almost entirely on teleosts, primarily Spratelloides delicatulus (Clupeidae). Principle components analysis of the dietary relationship between apogonids suggested a clear separation between species (Fig. 4A) with $56.9 \%$ of the variance accounted for by PC1 and PC2. Diet taxon vectors (Fig. 4B) indicated that PC1 was driven primarily by planktonic versus benthic taxa, whereas PC2 appeared to be driven largely by prey size. A plot of PC1 scores versus height of fish in the water column (Fig. 5) showed a strong correlation (Pearson's correlation, $r=-0.89$, $\mathrm{df}=5, \mathrm{p}<0.01$ ), suggesting that species in similar feeding habitats have similar diets. For example, Apogon doederlini and A. guamensis are both found primarily in the water column above the reef at night (Table 1, Fig. 2B), and both feed mostly on planktonic prey taxa (Table 2, Fig. 4). By comparison, A. doederlini and A. exostigma feed close to the substrate (Table 1, Fig 2B) and both consume mostly benthic prey taxa (Table 2, Fig. 4).

\section{DISCUSSION}

Daytime habitat overlap among apogonids contrasted greatly with the marked segregation of apogonids into discrete foraging locations at night. Apogonids were found to share restricted resting habitats during the day, mainly along the slope and base of micro-atolls. This was not surprising, considering that

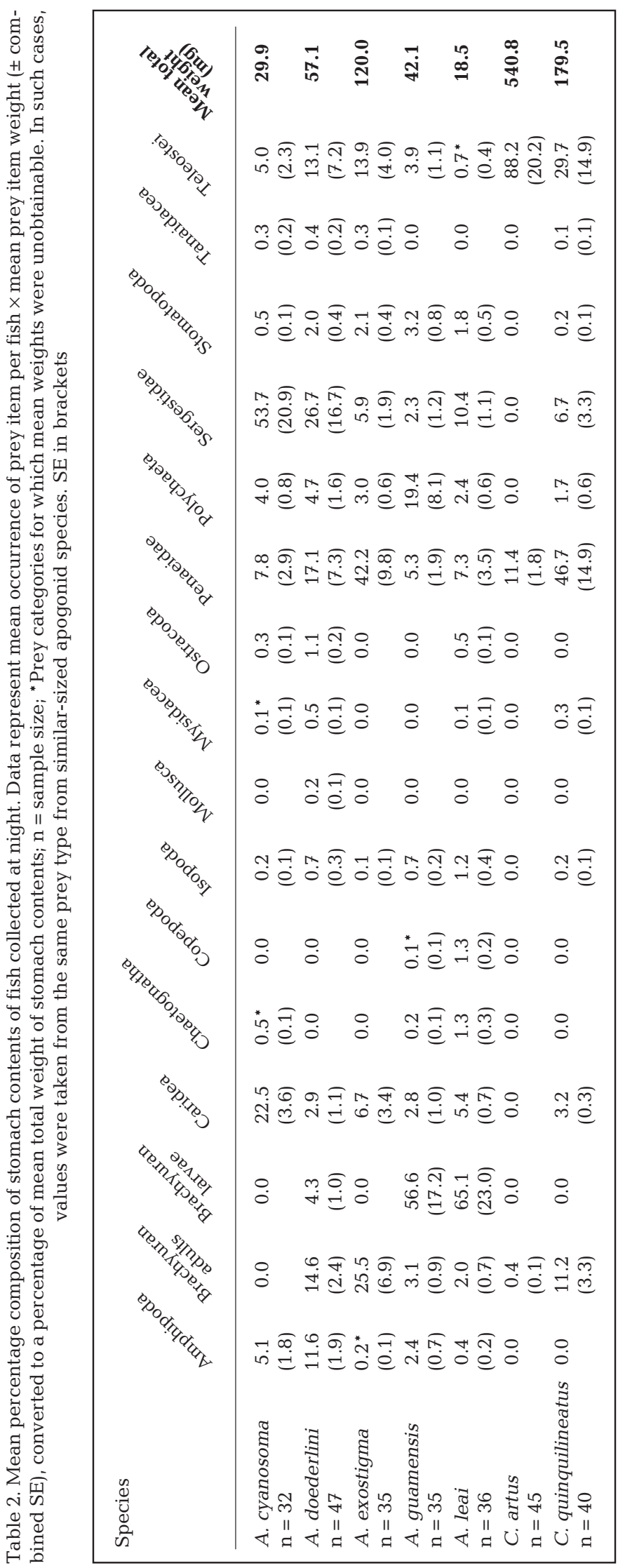


A)
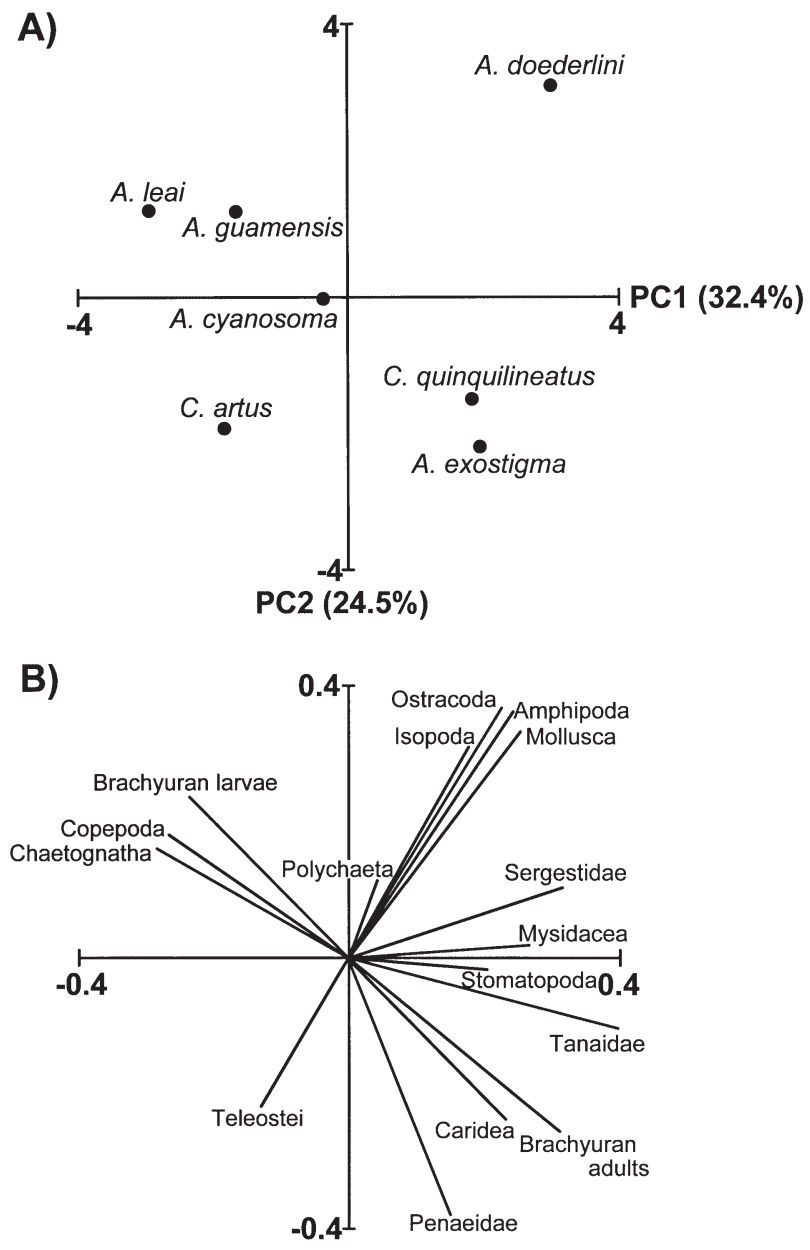

Fig. 4. Principle components analysis of dietary relationships: (A) species eigenvalues on principle components 1 and 2; (B) prey category eigenvectors

these zones have a high degree of topographic complexity, and are therefore likely to provide the greatest protection from diurnal predators (Hixon \& Beets 1993). Species were distinctly separated during the night, both horizontally and vertically. Surprisingly, patterns of spatial segregation appeared to operate over scales of $O(10 \mathrm{~cm})$ vertically and $O(1 \mathrm{~m})$ horizontally.

Spatial niche partitioning has been reported in a number of diurnal reef fishes, across many spatial scales including microhabitat, reef zone, level of exposure and depth gradients (Williams 1991) but has rarely been documented in nocturnal reef fishes at night. Gladfelter (1983) described spatial niche separation of 8 species of holocentrids into different reef zones in the West Indies. Burke (1995) described segregated habitat use of seagrass beds and sand habitats in 2 species of haemulids from Belize. The habitat division observed among apogonids was of a finer scale

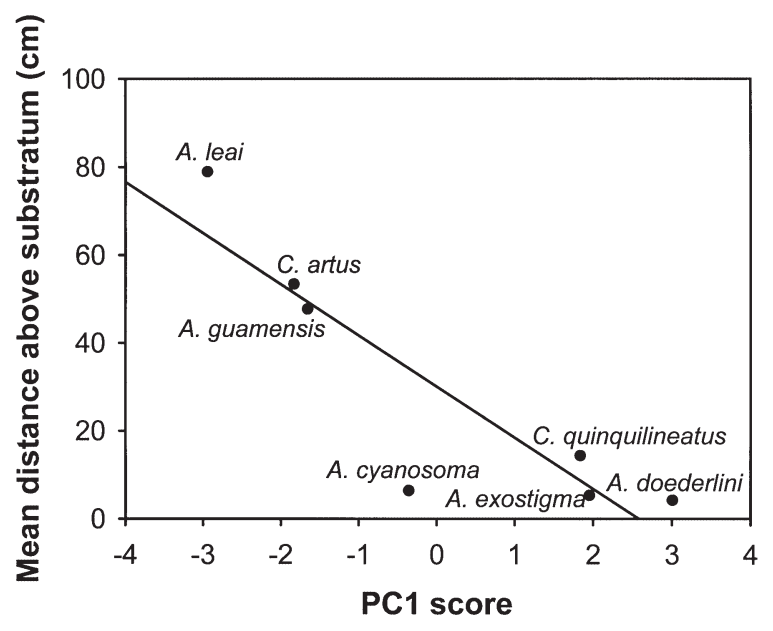

Fig. 5. Relationship between PC1 scores (see Fig. 4) and mean foraging heights of fish above the substratum at night (see Fig. 2B)

than previously observed in nocturnal fishes and was finer than that seen in most diurnal fishes. It is not known if this is due to strong habitat preference or competitive exclusion. The former might be expected, but intense aggressive interactions observed between apogonids in aquaria at night (pers. obs.) suggest that competition may play an important role.

To our knowledge, this is the first study to quantify nocturnal distribution patterns in reef fishes using relatively unbiased survey techniques. Previous distribution studies of nocturnal reef fish have either: examined diurnal distributions only (e.g. Greenfield \& Johnson 1990), used qualitative observations at night (Starck \& Davis 1966, Hobson 1974, Chave 1978), or used standard visual methods with a continuous light source to census fish at night (e.g. Gladfelter 1983, Burke 1995). Surveying nocturnal fish during the day is of limited utility because they are generally inactive and their position may not reflect feeding locations (Nagelkerken et al. 2000). Surveys conducted at night with a continuous light source are likely to enhance diver biases for species which display photo responses. These biases are difficult to measure and correct. The 'brief-illumination' technique used in the present study provides a quantitative alternative to previous survey methods. When moving between census points using only moonlight, fish showed little response to diver presence. Replacing the 'brief illumination' with infrared visual or video censuses may provide a useful refinement of this method.

The majority of apogonid species examined in this study appear to be primarily nocturnal in their feeding behaviour, as noted in previous studies (Vivien 1975, Chave 1978, Fishelson et al. 1997). The only possible exception to nocturnal feeding was in Apogon cyanosoma, which contained identifiable prey items in the 
stomachs of a relatively large proportion (36\%) of specimens collected at dusk. A. cyanosoma may supplement nocturnal feeding with diurnal or crepuscular feeding. Vivien (1975) suggests that A. cyanosoma may ingest some prey during the day based on gut content analysis. However, the exact time at which specimens were collected was not specified (only 'day' versus 'night'), which may limit resolution if crepuscular feeding was involved.

Apogonids are likely to play a role in concentrating nutrients and energy from a range of foraging habitats into localised, predictable resting sites on the reef. After a nocturnal foraging period, the majority of individuals returned to the same resting sites on the reef (Marnane 2000). Data suggest that these sites are maintained on a daily basis for periods of several months to years (Kuwamura 1985, Okuda \& Yanagisawa 1996, Marnane 2000). At dawn most individuals still have a large quantity of material in their guts (Fig. 3) and a significant proportion of this material is likely to be deposited at resting sites. This accrual of material, in the form of fish biomass and faeces, is likely to provide a spatially and temporally predictable resource for predators and detritivore communities (cf. Bray et al. 1981). The most striking example of this is Apogon doederlini which feeds almost exclusively over sand areas between micro-atolls and returns to shelter sites within the reef slope and base.

Apogon doederlini is highly abundant within the One Tree Reef lagoon, with adult densities commonly between 10 and 20 fish per $\mathrm{m}^{2}$ at resting sites (M.J.M. unpubl. data). A. doederlini may therefore be a key species responsible for gathering nutrients and energy from sand areas within the lagoon and concentrating these at resting sites on the reef. A. cyanosoma may play a similar role, moving material from foraging grounds on the reef flat to resting sites at the reef base. Apogonid faeces may be particularly important as it delivers nutrients to a localised area in a particulate rather than a suspended form, which would retain material within the reef system (i.e. within the boundary layer) (cf. Baird \& Atkinson 1997). Previous studies on haemulids in the Caribbean (Meyer et al. 1983) identified fish waste as a potential source of nutrients to enhance coral growth. In this respect, apogonids sheltering within corals may exhibit a symbiotic relationship, with the corals providing shelter whilst apogonids enhance local coral growth via nutrient enrichment.

Apogonids are largely generalist feeders. Dietary analysis (Table 2) indicated that all of the species examined, with the exception of Cheilodipterus artus, ate a wide range of organisms. C. artus preyed mostly upon clupeids, and is likely to be trophically similar to diurnal piscivores such as serranids, which also feed largely on clupeids within the lagoon (Kingsford 1992).
The prey consumed by the majority of apogonid species included a large proportion of benthic taxa and demersal plankton (e.g. brachyurans, sergestid shrimps, and polychaetes), whilst holoplanktonic forms such as chaetognaths and copepods represented only minor dietary components. It is possible that small, holoplanktonic prey undergo a more rapid digestion than larger benthic and demersal prey, and may therefore be under-represented in samples of stomach contents. However, even if a 10-fold difference in digestion rates was assumed, benthic taxa and demersal plankton would still dominate apogonid diets. In a trophic sense, apogonids play a functional role that is distinctly different to that of most diurnal planktivores, which generally consume oceanic plankton (Hobson \& Chess 1978). Apogonids are more likely to play a role of recycling in reef systems rather than of importing nutrients and energy to reefs from open water systems (cf. Hamner et al. 1988).

Some dietary separation was found among apogonids, despite their generalised diets. Dietary separation was primarily benthic versus planktonic prey and secondarily small versus large prey. This separation appears to be strongly linked with the position of species within the water column. Species that were high in the water column (e.g. Archamia leai and Apogon guamensis) consumed mostly small, planktonic prey whilst species that foraged low in the water column (e.g. A. doederlini and A. exostigma) consumed mostly large, benthic prey. Taxon-specific differences in the distances demersal plankton migrate vertically into the water column at night have been observed (Alldredge \& King 1985), supporting the conclusion that dietary separation in apogonids is associated with the species foraging locations within the water column. However, the question remains as to whether the feeding preference of apogonids determines their position in the water column or whether position in the water column dictates the availability of prey taxa.

The present study emphasises the need for data beyond gut contents and diurnal distributions if we are to understand the trophic roles of nocturnal fishes. In the case of apogonids, nocturnal behaviour appeared to be the main factor determining the functional role of each species. This study highlights the need to match methods to questions: both diurnal and nocturnal distribution data as well as dietary information are necessary to infer the trophic roles of nocturnal fishes on reefs. The high abundances and rapid turnover rates of apogonids on Indo-Pacific reefs suggests that they are important in reef tropho-dynamics. Given their strongly segregated feeding and shared resting locations, apogonids may play a key role in the transfer of nutrients between habitats and in the concentration of nutrients at specific sites on reefs. 
Acknowledgements. We wish to thank the staff of the One Tree Island Field Station for their support, J. Semmens, G. Pecl, M. Peters, S. Klanten, N. Gust and M. Schubert for field assistance, S. Wilson and R. Fisher for helpful discussions, and 4 anonymous reviewers for helpful improvements to the manuscript. This work was funded by the Mazda Foundation, the Australian Coral Reef Society and James Cook University Doctoral Merit Research Grants (to M.J.M.). The work was approved by the JCU Experimental Ethics Committee, approval no. A431.

\section{LITERATURE CITED}

Ackerman JL, Bellwood DR (2000) Reef fish assemblages: a re-evaluation using enclosed rotenone stations. Mar Ecol Prog Ser 206:227-237

Alldredge AL, King JM (1985) The distance demersal zooplankton migrate above the benthos: implications for predation. Mar Biol 84:253-260

Allen GR (1993) Cardinalfishes (Apogonidae) of Madang Province, Papua New Guinea, with descriptions of three new species. Revue fr Aquariol 20:9-20

Baird ME, Atkinson MJ (1997) Measurement and prediction of mass transfer to experimental coral reef communities. Limnol Oceanogr 42:1685-1693

Bellwood DR (1996) The Eocene fishes of Monte Bolca: the earliest coral reef fish assemblage. Coral Reefs 15:11-19

Bray RN, Miller AC, Geesey GG (1981) The fish connection: a trophic link between planktonic and rocky reef communities? Science 214:204-205

Burke NC (1995) Nocturnal foraging habits of French and blue-striped grunts, Haemulon flavolineatum and H. sciurus, at Tobacco Cay, Belize. Env Biol Fishes 42:65-374

Chave EH (1978) General ecology of six species of Hawaiian cardinalfishes. Pac Sci 32:245-270

Dale G (1978) Money-in-the-bank: a model for coral reef fish coexistence. Environ Biol Fishes 3:103-108

Finn MD, Kingsford MJ (1996) Two-phase recruitment of apogonids (Pisces) on the Great Barrier Reef. Mar Freshw Res 47:423-432

Fishelson L, Sharon O (1997) Spatial and foraging behaviour, diet and morphogenesis of postlarvae and juveniles of Pempheris vanicolensis in the Gulf of Aqaba, Red Sea. J Fish Biol 51:251-265

Fishelson L, Goren M, Gon O (1997) Black gut phenomenon in cardinalfishes (Apogonidae, Teleostei). Mar Ecol Prog Ser 161:295-298

Gladfelter WB (1983) Feeding niche separation in a guild of tropical reef fishes (Holocentridae). Ecology 64:552-563

Greenfield DW, Johnson RK (1990) Heterogeneity in habitat choice in cardinalfish community structure. Copeia 1990: $1107-1114$

Hamner WM, Jones MS, Carleton JH, Hauri IR, Williams DMcB (1988) Zooplankton, planktivorous fish and water currents on a windward reef face: Great Barrier Reef, Australia. Bull Mar Sci 42:459-479

Hiatt RW, Strasburg DW (1960) Ecological relationships of the

Editorial responsibility: Otto Kinne (Editor),

Oldendorf/Luhe, Germany fish fauna on coral reefs of the Marshall Islands. Ecol Monogr 30:65-127

Hixon MA, Beets JP (1993) Predation, prey refuges, and the structure of coral-reef fish assemblages. Ecol Monogr 63: $77-101$

Hobson ES (1974) Feeding relationships of teleostean fishes on coral reefs in Kona, Hawaii. Fish Bull 72:915-1031

Hobson ES (1991) Trophic relationships of fishes specialised to feed on zooplankters above coral reefs. In: Sale PF (ed) The ecology of fishes on coral reefs. Academic Press, San Diego, p 69-95

Hobson ES, Chess JR (1978) Trophic relationships among fishes and plankton in the lagoon at Enewetak Atoll, Marshall Islands. Fish Bull 76:133-153

Hobson ES, Chess JR (1979) Zooplankters that emerge from the lagoon floor at night at Kure and Midway Atolls, Hawaii. Fish Bull 77:275-280

Kingsford MJ (1992) Spatial and temporal variation in predation on reef fishes by coral trout (Plectropomus leopardus, Serranidae). Coral Reefs 11:193-198

Kuwamura T (1985) Social and reproductive behaviour of three mouthbrooding cardinalfishes, Apogon doederlini, A. niger and A. notatus. Environ Biol Fishes 13:17-24

Livingston RJ (1971) Circadian rhythms in the respiration of eight species of cardinalfishes (Pisces: Apogonidae): comparative analysis and adaptive significance. Mar Biol 9: 253-266

Marnane MJ (2000) Site fidelity and homing behaviour in coral reef cardinalfishes (family Apogonidae). J Fish Biol $57: 1590-1600$

Meyer JL, Shultz ET, Helfman GS (1983) Fish schools: an asset to corals. Science 220:1047-1049

Nagelkerken I, Dorenbosch M, Verberk WCEP, Cocheret de la Morinière E, van der Velde G (2000) Day-night shifts of fishes between shallow-water biotopes of a Caribbean bay, with emphasis on the nocturnal feeding of Haemulidae and Lutjanidae. Mar Ecol Prog Ser 194:55-64

Ogden JC, Erlich PR (1977) The behavior of heterotypic resting schools of juvenile grunts (Pomadasyidae). Mar Biol 42:273-80

Okuda N, Yanagisawa Y (1996) Filial cannibalism by mouthbrooding males of the cardinalfish, Apogon doederlini, in relation to their physical condition. Environ Biol Fishes 45: 397-404

Parrish JD (1989) Fish communities of interacting shallowwater habitats in tropical oceanic regions. Mar Ecol Prog Ser 58:143-160

Starck WA, Davis WP (1966) Night habits of fishes of Alligator Reef, Florida. Ichthyologica 38:313-356

Travis J (1982) A method for the statistical analysis of timeenergy budgets. Ecology 63(1):19-25

Vivien ML (1975) Place of apogonid fish in the food webs of a Malagasy coral reef. Micronesica 11(2):185-196

Williams DMcB (1991) Patterns and processes in the distribution of coral reef fishes. In: Sale PF (ed) The ecology of fishes on coral reefs. Academic Press, San Diego, p 37-474

Zar JH (1984) Biostatistical analysis, 2nd edn. Prentice-Hall, Englewood Cliffs, NJ

Submitted: January 25, 2001; Accepted: June 26, 2001

Proofs received from author(s): April 9, 2002 